\title{
The Legislative Confrontation of The Cyber Stalking Crime: A Comparative Study
}

\section{Dr. Fahad Alkasasbeh, Dr. IbtIsam Al Saleh}

Assistant professor - faculty of law, Amman Arab University ,amman -jordan

Dr.fahadalkasassbeh@yahoo.com

Assistant professor - faculty of law, Amman Arab University , Amman - jordan

Ibtisam_saleh@yahoo.com

\begin{abstract}
This study examined the legislative confrontation of the cyber stalking crime and focused on how the Jordanian legislator and the comparative regulations confront this modern crime. In addition, the study used the descriptive methodology that relies on describing the legal texts of the legal framework and it also used the analytical methodology in order to reach a correct adaptation of this crime. On the other hand, the study used the comparative methodology when conducting comparison among the comparative legal texts. Accordingly, due to the severe impact of harassment on man and the fact that it is considered the most common and widespread phenomenon after the emergence of information technology, many western legislations have been interested in confronting and criminalizing it in contrast to the Jordanian legislator and the comparative Arab legislations that have not yet examined the text of this crime and the threat is represented mostly in such act. The act threat of harassment that we deal with including the newly developed Arab legislations regarding is concerned in combating cybercrime.
\end{abstract}

Keywords:

Legislative Confrontation, Cyber Stalking Crime, information technology

Article Received: 18 August 2020, Revised: 3 November 2020, Accepted: 24 November 2020

\section{Introduction}

In the late twentieth century and because of the progress of which the western countries reached in respect as well as their interest in the rights of the citizen that have to be protected from any harm that might affect him, whether this harm is a physical or a psychological one, criminal laws in some western countries began to criminalize the pattern of behavior that might cause the victims' distress, suffering and inconvenience or the fear or disease, and sometimes it may be the reason for the occurrence of other crimes such as murder and rape.

This includes many actions that may be threatening to the victim or monitoring him, i.e. intrusive pursuit of the targeted person, such as staying for a long time in front of his home, doing continuous surveillance, appearing unexpectedly and unwelcome in the victim's private area, Or impeding him to reach his place of work or residence or any other place or to send unwanted letters and phone calls and parcels, whether or not they include a threat, or to act in any way that causes frightens the targeted person of affects his safety.

Furthermore, the scientific progress had significantly affected the harassment acts, as people began to realize it with the beginning of the spread of mobile phones and their use by callers who use obscene language and due to repeated and unknown communications or those that contain a threat not to forget the emergence of 
modern information technology and its spread. This shows the speed with which technology adapts modern information with criminal goals. However, recently, the role of information technology has not only provided criminals with a wide range of modern methods of committing harassment acts, but also helped to overcome the traditional difficulties that prevented the achievement of committing many harassment acts that the perpetrator cannot do face to face.

Similarly, a new criminal phenomenon which jurisdiction refers to as "Cyber Stalking" has appeared. Such a phenomenon represents a real challenge for the efficiency of the traditional criminalization texts in confronting such crimes.

The problem of the study is represented in the fact despite all of the procedures and development implemented by the Hashemite Kingdom of Jordan in terms of activating the cyber crime law No. (27) of 2015 and amendments in the year (2018) to limit cyber crimes, but not clear text stipulates punishment for such crime.

Keyword: Stalk

Means of modern IT, threat, email and legality principle

\section{Definition of Cyber Stalking}

The term (Stalking) is defined as an unwanted and repetitive intrusive behavior that causes fear and emotional or physical harm to the victim. It is a complex phenomenon with a series of motivations including hatred, jealousy, obsession, or love for exercising control or dominate on the others (Purcell, Pathe ,Mullen ,2004, p: 157).

In the legal texts that examined harassment crimes, the word (Stalk) means committing a repeated conduct with an intention to cause harm to the victim or cause fear or to provoke his fear or fear for his safety or the safety of others (Clough, 2010, p: 369). These texts were not limited in the threat but also included any conduct that may cause a psychological or emotional suffering (Goodno. 2007, p: 125).

Some scholars define the cyber stalking and online harassment crime as is an emotional terror by using means of modern information technology to instill fear of harm or death in a person. It is also a form of psychological or intellectual aggression, whereby the perpetrator repeatedly and in an undesirable appearance penetrates the victim's world without having a relationship with her or if this relationship no longer exists, and with direct or indirect motives it can be traced back to the emotional sphere. In general, in the field of the crime of harassment, the following characteristics or a set of characteristics are taken into consideration: malice, premeditation, severity, repetition and illegal purpose/s (Laughryn,2000, p:27).

However, it is believed that cyber stalking crime is defined as: the pattern of behavior that is directed at a specific person through the use of modern information technology means with the intention of annoying, harassing, pressuring, threatening or intimidating him, and in other words with the intention of causing him psychological and emotional harm and sometimes physical harm.

The perspective of western legislations from the cyber stalking crime

The French legislator did not stipulate a specific provision for harassment through modern information technology means, but the French code devoted a special chapter on acts of harassment under the title of assault or harming the safety and security of persons, which included criminalizing the actions that cause psychological pain for people or make them vulnerable to it due to harassment. For example, Article 422 stipulated in the Law of October 30, 1998, stipulates the punishment of anyone who matches a person who knows or is supposed to know that his behavior 
seriously affects the tranquility of the targeted person (Jafar, 2013, p. 281).

Article (2-33-222) of Law No. (73) That was issued in January, 2002 indicates to the following:

Harassing another person by repeated conduct which is designed to or which leads to a deterioration of his conditions of work liable to harm his right and his dignity, to damage his physical or mental health or compromise his career prospects is punished by a year's imprisonment and fine of the offender for the amount of $(15,000 €)$.

In Britain, the Act of Protection from Harassment that was issued in 1997, which stipulates that a person should not conduct any behavior that amounts to harassing another person while he knows or is supposed to know that his behavior is offensive to others (Finsh, 2002, p: 703).

The forth part of the protection law stipulated for the more serious act that the conduct (the course of conduct) shall be repeated at least in two occasions that do not cause fear, harm or violence that might be used against him (Claugh, 2010, p: $370)$.

In the United States of America, most states have introduced special legislations on harassment crimes through modern information technology in addition to texts on traditional harassment crimes (Goodno, 2007, p125).

In this regard, on the federal level harassment is subject to this through law (18 USC 2261A). It was amended to include modern technology means. According to this law, the crimes of using the email or any e-means that is activated through computer to engage in a repeated conduct that may cause pain and emotional distress or make him frightened of death of fear for his safety.

Safety: is defined to include a person's "mental well being "or the sake of any of his family members, brothers or anyone with whom he cares.
By reading the previous sample of harassment legislations, it becomes clear that legislators, in their determination of the element of behavior or criminal activity in the material element of the crime of harassment, have followed one of two methods, either not stipulating the determination of the acts that constitute the punishable behavior in the crime of harassment and contentment with using the phrase "repetitive or group behavior. Course of conduct, is a term that is adopted by both the US federal law and the British law, which stipulates that the behavior takes place at least twice. This term has been adopted by both US federal law and the British law, which stipulate that the behavior should occur at least twice.)

\section{Protection}

"From Harassment Act 1997 (UK): Even where there are two incidents, the circumstances must be such that they may properly be described as a course of conduct".

This method of determining the element of criminal behavior in the material element of the crime of harassment bears the benefit of flexibility as it gives courts greater appreciation in terms of law enforcement, especially with regard to modern and unfamiliar forms of harassment, but at the same time it is critical of its contravention of the general principle that states that there should be a definition of acts. According to the criminal law, such act is banned.

(This concept is given constitutional protection under the due process clause of the fourteenth amendment to the US constitution) "See generally: A. Packerd Does proposed federal cyberstalking legislation meet constitutional requirements -: Communication law and policy 2000".

In fact, there is a need to stipulate a clear text that contains a specific definite list of acts that represent a harassment behavior, for example the Canadian Penal Code stipulated that the acts that 
constitute the offense of harassment are defined as follows:

- Stalking someone over and over from one place to another.

- Unwanted contact with a person repeatedly, directly or indirectly.

- Constantly staring at a person or watching his home in which he lives, his place of work, or any place he frequents

- A direct threat to a person or any of his family members (Criminal Code, Canada, S. 264 (2).

The perspective of the Jordanian legislation and some Arab legislations on Cyber stalking crime

The concept of the crime of harassment in the Arab world has not been crystallized in the way that happened in Western countries, so that most Arab legislations have not stipulated the crime of harassment, whether it occurred in its traditional form or through modern information technology.

Although there are some texts of the legislations that may address the issue of emotional harm and harassment / including what has been stipulated in Article 298 of the UAE Federal Penal Code, a penalty of imprisonment for a period not exceeding one year or a fine not exceeding ten thousand Dirhams shall be imposed on anyone who intentionally causes inconvenience to others by using transportation devices Wired and wireless. This is what was stipulated in Article 166 (repeated in the Egyptian Penal Code, and Article 393 of the Iraqi Penal Code).

It could be said that the threat is almost the only act of harassment that was dealt and examined by Arab legislations, including the new Arab legislation regarding combating information technology crimes. The threat is one of the acts that constitute the element of criminal behavior in the crime of harassment through modern information technology means, such as if a person threatens another through A forum spread on the Internet or through chat and chat rooms.

First: Threat crime in the Jordanian penal code

The legislator spoke about the crimes of threatening people in Articles (349-354) of the Penal Code. Some of these crimes are of the reconciliation misdemeanor type, some are of the primitive misdemeanor type, and some are of the violation type.

The threat may be considered a first misdemeanor punishable by imprisonment from 6 months to 3 years in the event that the perpetrator threatens another person with a felony whose penalty is not less than death or permanent labor or more than fifteen years, whether by closed writing or by a third person, provided that the warrant includes the order Conducting or abstaining from an action, even if it is legitimate.

According to Article 351, a threat may be considered a reconciliation misdemeanor, if the threat to one of the aforementioned felonies does not include an order or included an order, but it occurred verbally without the mediation of a third person, then he / she shall be punished based on the victim's complaint by imprisonment from one month to two years.

In this regard, Article 349 stipulates on punishment with imprisonment for a period not exceeding six months for anyone who threatens another one month with a firearm. The punishment ranges between two months and a year if the perpetrator uses a firearm.

The text on the threat of a breach of the type was mentioned in Article (345) "penalties", which stipulates: "Every other threat to inflict unjust harm, if it occurs by word or by any of the means mentioned in Article (73) and that would severely affect the victim's soul, he will be punished with imprisonment for up to a week or a fine not exceeding five Dinars (Ahmed, 2016, p: 218-220). 
Second: The applicability of the traditional texts contained in the Jordanian Penal Code, in the event that they occur through information technology means

In this context, the Jordanian legislator remained silent in defining the act of threatening and left it to the jurists. The threat is that act that a person undertakes to warn another of a danger that he wants to impose on his person or his money or the person or money of others, and it is equal for that warning to be verbally or in writing by any phrase that would cause terror in the soul Or the money or offer of any person of interest to him, and considering the statement as a threat does not negate the fact that the phrases are wrapped with some ambiguity, whenever they would have the intended effect on the soul of whom they were directed to (Ahmed, 2016, p .: 221).

As a result, it is not necessary for the perpetrator to carry out any of the elements of the crime he is threatened with. Rather it is sufficient for this threat to be of a degree of seriousness that would intimidate the victim, undermine his security and reassurance and lead him to believe that the perpetrator will implement what he threatens. It is for honor or disclosure to take place by one of the methods of publicity. Rather, threatening to divulge to a single person or secretly suffices, because this achieves the same effect by throwing fear and terror in the soul of the victim, just as it does not matter whether the matters threatened are correct or invented. (Al-Kaibi, 2005, p.88).

As we mentioned before, the Jordanian legislator handled the threat crime and allocated specific legal texts for it, where he presented its forms, shapes, aspects and components.

Article (345) Jordanian penalties stipulated on the general rule and the general model for the crime of threat, where it mentioned the phrase (any other threat). Therefore, with the ability to read this text and the text of Article (73/4), of the same law that searches in public, it was considered a means of publicity.

Writing, drawings, hand and solar photos, films, badges and photography in their contradiction if they are displayed in a public place, an open place to the public, an exhibition of sight, sold, offered for sale, distributed to more than one person, or published by electronic means that enable the public to read or view them without restriction. It is also possible to adapt this text to include many forms of electronic threat, and to include this new model of crime within the logic of the text (every other threat), taking into account that the previously mentioned threat texts that have discussed the types of traditional threat, it is indispensable for penal texts that deal with the electronic threat as a deterrent punishment for him. (Al-Mana'sa, Al-Zoubi, 2017, p. 255).

This remained the case until the enactment of the Cybercrime Law of 2015, which in the first paragraph, Article 3 of which spoke about unauthorized access to the electronic data and information processing system, then indicated the cases, goals and objectives of the perpetrator of illegal access in Paragraph 2. However, this law did not offer what was expected, as it did not include among the forms of behavior the investigation of access and data and information with the intention of threatening, extorting or disturbing the victim and causing psychological and emotional pain for the victim (ibid).

Third: The crime of threatening the Arab private legislations

In this context, the Arab guiding law for combating information systems technology crimes in Article (9) stipulates on the following: Whoever uses the information network or a computer device and the like to threaten or blackmail another person to compel him to do or refrains from doing it, even if this act or omission is lawful, it is punishable by imprisonment and a fine, or one of these two penalties. 
Moreover, this was stipulated in Article (3) of the Saudi Law to Combat Information Technology Crimes, and Article (9) of the Federal Law Concerning Combating Information Technology Crimes Law in the United Arab Emirates.

\section{Components of Cyber Stalking Crime}

Cyber stalking crime does not differ from any other traditional crime established in the penal code in that it requires for its fulfillment the consistent elements as it must be achieved in any crime in order to be present on the ground, in addition to the necessity of having the initial condition in each crime and we mean here the legal element, it must The existence of a tangible material element that clearly expresses the will of the perpetrator can be proven, and then there must also be a moral element that expresses the will of the criminal, modern information technology.

\section{First: the legal component}

The legal component means (no crime and no punishment without a text/ evidence). This means there should be a text that prohibits and punishes the crime; the law is required to consider the act as a crime and there should be a text that criminalized this act and punishes it. This is called the principle of legality; the legal component is talking legality from criminalization through the legal texts. Originality in this is permissibility until a text that stipulated criminalization (AlQahwaji, 2002, p. 65).

First: the material component of the cyber stalking crime

The material element means the external appearance of the crime and its face in which it appears and through it, the assault on the protected interest is achieved, and the operational actions of the crime take place (Sorour, 1985, p. 308).

The material element has a clear importance, as the fact that the crime is based on tangible materials that makes establishing evidence for it easy. The prevailing principle in modern positive laws is that criminalization only applies to material acts, that is, external manifestations that can be touched in the outer space in any way, and therefore not Criminalization deals with the thoughts, intentions, and beliefs that remain latent in the inner realm of the soul (Hosni, 267. 1989, p. 267).

In the analysis of the material component, we note that it is based on three components:

1- Criminal activity, which is the positive or negative behavior that the perpetrator commits to the protected interest, and this activity or act is realized in the crime of harassment when a person issues behaviors directed at a specific person that affect his psychological integrity and sometimes lead to compromising his physical integrity as well, and criminal activity in The crime of harassment by means of modern information technology takes many manifestations and is either direct or indirect.

Criminal activity in the crime of harassment through modern information technology means in its direct form -, may include sending e-mail messages from one person to another whose content is either offensive or obscene or causing the victim to feel threatened or in other words feeling fear and dread. (Cullen, 1997, p 217).

Moreover, the behavior of electronic harassment in its direct form on the form of sabotage, such as a bombing e-mail, where hundreds or thousands of unwanted e-mails are sent, i.e. what is known as (junk e-mail messages). Accordingly, this leads to the destruction of his mail, whether it is the postal address of a person or a company. The foreign jurisprudence demonstrates this activity in the term of (Spamming) and also viruses might be sent to the device which is used by the target person. (Graw, 1995 - p: 492)

As for the indirect form of criminal activity in the crime of harassment through modern information technology means, it may include spreading rumors about the victim on web pages, or posting 
false pictures or personal information about him, impersonating the victim in chat rooms and news groups, sending offensive, obscene or fraudulent messages and advertisements. In such cases, the victim's name is false and these messages may include the victim's address, phone numbers, and e-mail addresses.

Consequently, the victim becomes the one who subscribes hundreds of messages without his knowledge. As a result, he receives hundreds of abusive and unwanted e-mails and communications every day. On the other hand, the victim -in many cases- becomes vulnerable to tracking and monitoring many people who have seen the messages sent in his name, or who have spoken with his impersonator, so that the person is a victim of online or cyberspace harassment causes great discomfort and anxiety that amounts to fear, but the real and greatest fear is when the aggressive behavior and the threat that has arisen escalates The line, to reach stalking, surveillance and harassment in reality (real life). Fears have increased in several countries about the increase of this pattern of the criminal beach of electronic media and this is the number of cases that began with this pattern of electronic harassment and then led to incidents of assault, stalking, rape and murder (Al-Mana'sa, Al-Zoubi, 2017, p. 254).

For the occurrence of the of the material element, most legislations stipulate that the crime of harassment require that the criminal activity take place repeatedly at least twice (as stated in the British legislation on the crime of harassment), as the actions involved in the pattern of behavior in the crime of harassment, in their separate form, cannot cause the occurrence that is a desired criminal outcome. However, most of the legislations do not require that the act to which the description of harassment or persecution applies to the offense be repeated, in order for the perpetrator to be considered harassment in case this act constitutes an act of threat (ibid).
It is enough fur such crime is to take place once so as to form a harassment crime (Ja'far, 2013, p. 294-295).

2 - The criminal outcome: It is the impact or damage resulting from the criminal activity, and this harm in the crime of harassment through modern information technology means is the target person's feeling of real emotional distress or pain, or fear of death or fear for his safety or the safety of one of his family members or brothers Or any of the people he cares about. The criminal outcome has a clear significance, as the material element is not complete until the result is achieved, and if the crime was intended (Hosni 1998, 238).

3- Casual relationship: Casual relationship is the link between the criminal activity and the criminal outcome, and it has great importance in the material element, as it is not sufficient for this element to be established in the crime of harassment through modern information technology means for a criminal behavior to occur by the perpetrator and for a result to occur. In addition, this result must be based on that behavior. That is, there is a causal link between them that leads to the assertion that it is the behavior of the agent that caused this harmful outcome.

Second: the moral component of the harassment crime

It is the criminal intent or the desire and will with which the act of harassment is associated as the criminal intent is the main indicator to determine who is responsible for the crime. In this regard, no person is asked about a crime unless there is a relationship between its material and its psyche, and these materials are not reliable unless they are issued by a person who asks about them and bears the punishment. This means that it is chosen and the offender is aware of its meanings and consequences. 
Most of harassment legislations require that the perpetrator of the crime of harassment acts with the intention of causing the target to any emotional and psychological harm or with the aim of arousing his fears, as some of this requires evidence of this criminal intent. For example, the US federal law, require that the allegation should be proven that the accused acted with intent or recklessly when he harasses the victim. For instance, the Canadian Penal Code where some of them are satisfied that the accused has acted in any way that is reasonably expected to cause harm and psychological pain to the victim or that arouse his fears (ibid).

In Britain, the Protection from Harassment Act, issued in 1997, stipulated that a person should not behave in any manner that amounts to harassment of another person while he knows or is supposed to know that his behavior causes harassment to others. In France, Article 422 stipulated in the law (October 30, 1998) stipulates that anyone who harasses a person when he knows or is supposed to know that his behavior seriously affects the tranquility of the targeted person.

\section{Forms of cyber stalking crime}

Based on the above, we believe that harassment crime takes the following forms:

\section{The first form: Harassment via email}

The idea of e-mail is based on exchanging electronic messages, files, graphics, pictures, audio, programs... etc by sending them from the sender to one or more persons using the e-mail address of the sender. (Ahmad, 2015, p. 113)

Despite the tremendous benefits provided by this service, it turns into a devastating bomb that threatens people and their interests if misused and unsolicited e-mail with content is the most common forms of harassment via e-mail (Yousif, 2011, pp: 110-111).
Among the applications of the possible hateful or that contain offensive, obscene or threatening material, one of the manifestations of harassment through modern information technology means is that a high-ranking graduate from San Diego University of America committed the offense of harassing girls by sending many aggressive emails that include a threat, due to his belief that girls make fun of him (Dean, 2000, available at: www.wired.com/news/politics ).

In another case, the South Carolina District Court in the US, state of Columbia sentenced James Murphy, 38, to five years of probation, 500 hours of social service, and a fine of 12,000 US dollars, for using of modern information technology media for harassment, threats by sending electronic messages containing the previous descriptions to Joel Legon and other Seattle staff. The convict admitted that he had an affair with Joel Legon during the period between 1984 and 1990.

In May 2002, the convict began sending dozens of annoying and unwanted e-mails to Joelle and her co-workers, and the convict concealed his identity using a special e-mail program and created a group in the name of the anti-Joel fan club and sent threatening messages through this alleged group, moreover, he sent an e-mail containing sexually explicit material to Joel's colleagues in a way that showed Joel as the sender of this scandalous mail. (Jafar, 2013, p .: 300)

In Saudi Arabia, the Criminal Court in the AlAhsa region issued a one year and 10 months in prison sentence and 200 lashes in addition to a fine of 50,000 SR against a person who blackmailed a girl by hacking her email and obtaining her pictures and threatening to expose her. The verdict came in implementation of the Anti-Cyber Crime Law. In addition, a judicial court in the Khobar region issued a verdict on a young man with 60 lashes and 8 months imprisonment for a high school student, after he photographed his colleague and published his 
pictures on the Internet after distorting them and inserting some clips In them and sending them via e-mail (the verdict was published in Al-Watan on 8/21/ 2008, the Saudi newspaper).

\section{The second form: harassment through internet} (Chat), discussion forums, news groups and web pages.

Online communication is known as the speaking service used through devices connected to the internet (computers), where the user of this service who wants to communicate with someone writes the message that is displayed directly in front of the other person who wants to communicate with him, where the other responds in the same way, and it can be done by voice and the picture.

With the emergence of different tools such as internet, chat rooms and direct communication has become more popular among Internet users. Chat rooms and newsgroups have become one of the most popular and well-known chat systems in the field of internet communication and an important means that enables perpetrators of the crime of electronic harassment to identify and following up their victims, defamation and threaten them. In addition to using web pages, the user can, once logged in, perform functions such as uploading and downloading programs and data, read news and bulletins and exchange messages with other users through public message forums, which also allows chat rooms and users to interact with each other (Shawabkeh, 2011, 43-44).

When a person enters a chat room, his name appears on the screen and joins the list of the names of other person who are within the group. In such case, the electronic harassment takes the overt and public dimension instead of the private one. Therefore, when a person sends a public message to a news group conversation, this message becomes available to everyone so that anyone can see it and keep a copy of it. In addition to this, the person's name, email, and information about the service provider are easily available as part of the message itself, and these public messages through chat groups can be accessed by anyone at any time and even after years to write it down.

Consequently, the perpetrator can interrupt the conversation of the targeted person by electronic means or he targets the conversation system which makes it impossible for a person to continue a conversation with another person. Moreover, the perpetrator can enter in a direct conversation that offends the victim or he may leave an inappropriate message on the message board or in the chat rooms or even about the victim.

Moreover, among the cases is a former security guard - 50 years old - impersonating a 28 -year-old girl through chat rooms and web pages on the Internet. These conversations and advertisements included the girl's address and declaring her desire and fondness to be raped by men. For a year, she was exposed to six rape attempts by men who came to her house. (Maxwell, 2001, p: 6)

The third form: Harassment by targeting the victim's computer:

In this kind of electronic harassment, the perpetrator of the crime targets the victim's computer in a form of intimidation, or surveillance so the criminal who has the ability and technical competence can control access to the victim's computer to collect information, deletes or modifies data or to exercise control over a device victim's computer.

An example of this type of electronic harassment is the case of a woman who appeared on her computer screen with a message saying: "I will get you, and then the sender of this message opened the CD-ROM drive to prove to the woman that he was dominating her computer. (Jafar, 2013, p. 306).

Results 
Through our study that dealt with the legislative confrontation with the crime of electronic harassment (a comparative study), we were able to reach several results:

- The Jordanian Cybercrime Law does not guarantee the necessary legal protection for the crime of cyber harassment, because this law protects information and works without protecting the person from the harassment issued against him.

- The threat is almost the only act of harassment dealt with in the Jordanian and Arab legislations, including the new Arab legislations related to combating information technology crimes, but none of these legislations has been subject to the text of the crime of electronic harassment.

- The Jordanian jurisdiction, as well as the judiciary of Arab legislations, stands in a perplexed position in front of the crimes of electronic harassment, which prompts it to adapt it to another criminal adaptation.

\section{Recommendations:}

- The Jordanian legislator must intervene in enacting a legal text within the Cyber crime Law to confront the crime of electronic harassment.

- Not tolerating the perpetrators, along with the need to work on increasing legal awareness of the victims of this crime and providing them with protection.

\section{References:}

\section{Arab references}

1. Muhammad Obaid Al-Kaibi (2005), Crimes Arising from the Illicit Use of the Internet, Arab Mahdah House, Cairo.

2. Ali Abboud Jaafar (2013), Modern Information Technology Crimes against Persons and the Government, 1st Edition, Zain Human Rights Publications, Beirut.
3. Ahmed Fathy Sorour (1985), Mediator in the Penal Code, General Section), 4th Edition, Dar Al-Nahda Al-Arabiya, Cairo.

4. Mahmoud Naguib Hosni (1989), Explanation of the Lebanese Penal Code (General Section), 6th Edition, Dar AlTaqwa for Printing, Beirut.

5. Muhammad Amin Al-Shawabkeh (2011), Computer and Internet Crimes, Dar $\mathrm{Al}$ Thaqafa for Publishing and Distribution, Amman.

6. Kamel Al-Saeed (2009), Explanation of General Provisions in the Penal Code, House of Culture for Publishing and Distribution, Amman.

7. Abdul-Rahman Tawfiq Ahmed (2016), Explanation of the Penal Code / Crimes against Persons, Dar Al-Thaqafa for Publishing and Distribution, Amman.

8. Osama Ahmad Al- Mana'sa, Hilal Muhammad Al-Zoubi (2017), Electronic Information Systems Technology Crimes, Dar Al Thaqafa for Publishing and Distribution, Amman.

9. Yuosif Hassan Yuosif (2011), International Internet Crimes, National Center for Legal Publications, Cairo.

10. Ali Abdel-Qader Al-Qahwaji (2002), Explanation of the Penal Code, Al-Halabi Legal Publications, Beirut.

11. Tarek Afifi Sadiq Ahmed (2015), Mobile Phone Crimes, National Center for Legal Issues, Cairo.

\section{Foreign references}

12. Jonathan Clough (2010), Principles of Cyber Crime, Cambridge university press.

13. N. H. Goodno (2007) Cyberstalking a new crime: Evaluating the effectiveness of cur- 
(2) rent state and federal laws - Missouri Law Review

14. .Emily Finish ( (2000Stalking the perfect stalking law: An evaluation of the efficacy of (3) the protection from Harassment Act 1997 Criminal Law Review

15. Cullen P, QC (1997) Computer Crime " in Edwards L and Waelde C, (eds) Law and The Internet, Regulating Cyberspace Oxford, Hart Publishing.

16. Mac Graw - Sexual harassment in cyber space: The problem of unwelcome (1) Email 1995 - Rutgers computer and technology law journal -

17. K.Dean (2000) The epidemic of Cyber stalking - Wired news - available at : )www .wired .com / news / politics.

18. Medlin Amanda (2002) Stalking to Cyber stalking ,a Problem

19. Caused by the Internet Law and the Internet,Fall 2002 papers, Georgia State University Col ledge of Law,140www.gsula.gsu.edu

20. Angela Maxwell (2001) Cyber stalking Department of psychology-Auckland University

21. R. Purcell, M. Pathe and P. E. Mullen (2004) Stalking : Defining and Prosecuting a new category of offending - International Journal of Law and Psychiatry. 